\title{
Tattoo Sarcoidosis
}

\author{
Alexis Lyons, MD, Gretchen Brayman, MD, and Sami Tahhan, MD, FACP
}

Department of Internal Medicine, Eastern Virginia Medical School, Norfolk, VA, USA.

KEY WORDS: dermatology; sarcoidosis; skin; rheumatology; internal medicine.

J Gen Intern Med 33(1): 128

DOI: $10.1007 / \mathrm{s} 11606-017-4168-\mathrm{x}$

(C) Society of General Internal Medicine 2017

A 33-year-old previously healthy man presented with an asymptomatic rash on his tattoo. Physical examination revealed brown and black papules confined to the ink of his tattoos (Fig. 1a, b). Chest x-ray showed hilar lymphadenopathy. Biopsy of a papule on his tattoo demonstrated noncaseating granulomas consistent with a diagnosis of sarcoidosis.

Sarcoidosis is a granulomatous disease that can affect multiple organ systems, with skin involvement seen in approximately $25 \%$ of cases. ${ }^{1}$ Sarcoidal reaction at the site of tattooing is a well-described phenomenon. ${ }^{2,3}$ Skin findings in sarcoidosis typically do not have prognostic significance, with the exception of erythema nodosum and lupus pernio, which have been associated with spontaneously resolving sarcoidosis and more severe systemic involvement, respectively. ${ }^{4-6}$ The etiology of tattoo sarcoidosis is unknown, but it may arise from chronic antigenic stimulation in predisposed patients. ${ }^{3}$ The differential diagnosis for tattoo-associated skin lesions in sarcoidosis includes T-cell lymphoma, infection, keloid, and discoid lupus erythematosus. ${ }^{2,}{ }^{3}$ It is vital for practitioners to be aware of skin and tattoo involvement in sarcoidosis, as it is an easy and non-invasive site for biopsy and can aid in an early diagnosis and thus prompt treatment.

Corresponding Author: Alexis Lyons, MD; Department of Internal Medicine Eastern Virginia Medical School, 825 Fairfax Ave, Suite 410, Norfolk, VA 23507, USA (e-mail: alexisblyons@gmail.com).

\section{Compliance with Ethical Standards:}

Conflict of Interest: The authors declare that they have no conflict of interest.

\section{REFERENCES}

1. English JC III, Patel PJ, Greer KE. Sarcoidosis. J Am Acad Dermatol 2001;44(8):725.

2. Ayoola R, Mansour W, Gujral J. Tattoo rash. JAMA 2015;313(17):1747-8.

3. Torres L, Faiz S. Images in clinical medicine. Tattoos and sarcoidosis. $\mathrm{N}$ Engl J Med. 2014;370(23):e34.

4. Mana J, Marcoval J, Graells J, Salazaar A, Pyri J, Pujol R. Cutaneous involvement in sarcoidosis: relationship to systemic disease. Arch Dermatol 1997;133:882-8.

5. Hanno B, Needleman A, Eiferman RA, Callen JP. Cutaneous sarcoidal granulomas and the development of systemic sarcoidosis. Arch Dermatol 1981;117:203-7.

6. Mana J, Salazar A, Manresa F. Clinical factors predicting persistence of activity in sarcoidosis: a multivariate analysis of 193 cases. Respiration 1994;61:219-25.

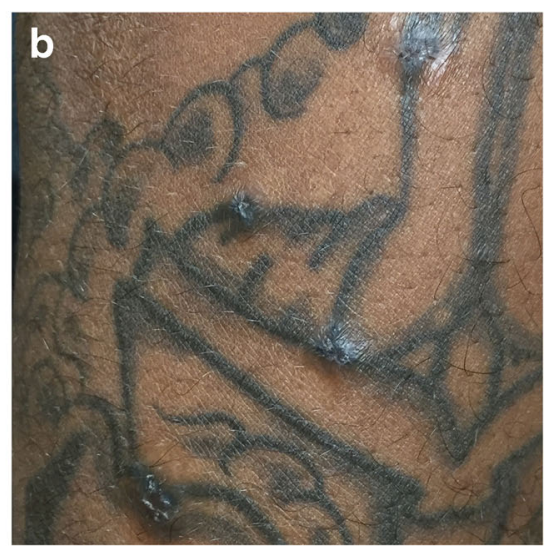

Figure 1 a, b Brown and black papules isolated to the ink of the patient's tattoos. 